\title{
Replacement of Chalcone-Ethers with Chalcone-Thioethers as Potent and Highly Selective Monoamine Oxidase-B Inhibitors and Their Protein-Ligand Interactions
}

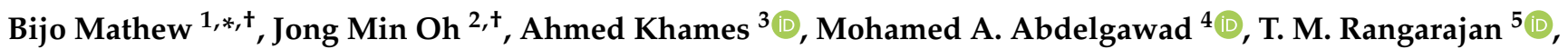 \\ Lekshmi R. Nath ${ }^{6}\left(\mathbb{D}\right.$, Clement Agoni ${ }^{7}$, Mahmoud E. S. Soliman ${ }^{7}$, Githa Elizabeth Mathew ${ }^{8}$ and Hoon Kim ${ }^{2, *}$ \\ 1 Department of Pharmaceutical Chemistry, Amrita School of Pharmacy, Amrita Vishwa Vidyapeetham, AIMS \\ Health Sciences Campus, Kochi 682041, India \\ 2 Department of Pharmacy, and Research Institute of Life Pharmaceutical Sciences, Sunchon National \\ University, Suncheon 57922, Korea; ddazzo005@naver.com \\ 3 Department of Pharmaceutics and Industrial Pharmacy, College of Pharmacy, Taif University, P.O. Box 11099, \\ Taif 21944, Saudi Arabia; a.khamies@tu.edu.sa \\ 4 Department of Pharmaceutical Chemistry, College of Pharmacy, Jouf University, Sakaka 72341, Saudi Arabia; \\ mhmdgwd@ju.edu.sa \\ 5 Department of Chemistry, Sri Venketeswara College, University of Delhi, New Delhi 110021, India; \\ rangarajan93150@gmail.com \\ check for \\ updates \\ Citation: Mathew, B.; Oh, J.M.; \\ Khames, A.; Abdelgawad, M.A.; \\ Rangarajan, T.M.; Nath, L.R.; Agoni, \\ C.; Soliman, M.E.S.; Mathew, G.E.; \\ Kim, H. Replacement of Chalcone- \\ Ethers with Chalcone-Thioethers as \\ 6 Department of Pharmacognosy, Amrita School of Pharmacy, Amrita Vishwa Vidyapeetham, AIMS Health \\ Sciences Campus, Kochi 682041, India; lekshmirnath@aims.amrita.edu \\ 7 Molecular Bio-Computation and Drug Design Laboratory, School of Health Sciences, Westville Campus, \\ University of KwaZulu-Natal, Durban 4001, South Africa; clegoni@gmail.com (C.A.); \\ soliman@ukzn.ac.za (M.E.S.S.) \\ 8 Department of Pharmacology, Grace College of Pharmacy, Palakkad 678004, India; githaliz@gmail.com \\ * Correspondence: bijomathew@aims.amrita.edu or bijovilaventgu@gmail.com (B.M.); \\ hoon@sunchon.ac.kr (H.K.) \\ + These authors contributed equally to this work.
} Potent and Highly Selective

Monoamine Oxidase-B Inhibitors and Their Protein-Ligand Interactions. Pharmaceuticals 2021, 14, 1148. https://doi.org/10.3390/ph14111148

Academic Editors: Paweł Kafarski and Joachim Jose

Received: 18 October 2021

Accepted: 9 November 2021

Published: 11 November 2021

Publisher's Note: MDPI stays neutral with regard to jurisdictional claims in published maps and institutional affiliations.

Copyright: (C) 2021 by the authors Licensee MDPI, Basel, Switzerland. This article is an open access article distributed under the terms and conditions of the Creative Commons Attribution (CC BY) license (https:// creativecommons.org/licenses/by/ $4.0 /)$.
Abstract: To develop new potent and highly selective MAO-B inhibitors from chalcone-thioethers, eleven chalcones-thioethers were synthesized and their monoamine oxidase (MAO) inhibition, kinetics, reversibility, and cytotoxicity of lead compounds were analyzed. Molecular dynamics were carried out to investigate the interactions. Compound TM8 showed potent inhibitory activity against MAO-B, with an $\mathrm{IC}_{50}$ value of $0.010 \mu \mathrm{M}$, followed by TM1, TM2, TM7, and TM10 $\left(\mathrm{IC}_{50}=0.017,0.021\right.$, 0.023 , and $0.026 \mu \mathrm{M}$, respectively). Interestingly, TM8 had an extremely high selectivity index (SI; 4860) for MAO-B. Reversibility and kinetic experiments showed that TM8 and TM1 were reversible and competitive inhibitors of MAO-B with $\mathrm{K}_{\mathrm{i}}$ values of $0.0031 \pm 0.0013$ and $0.011 \pm 0.001 \mu \mathrm{M}$, respectively. Both TM1 and TM8 were non-toxic to Vero cells with $\mathrm{IC}_{50}$ values of 241.8 and $116.3 \mu \mathrm{g} / \mathrm{mL}$ (i.e., 947.7 and $402.4 \mu \mathrm{M}$ ), respectively, and at these $\mathrm{IC}_{50}$ values, both significantly reduced reactive oxygen species (ROS) levels. TM1 and TM8 showed high blood-brain barrier permeabilities in the parallel artificial membrane permeability assay. Molecular dynamics studies were conducted to investigate interactions between TM1 and TM8 and the active site of MAO-B. Conclusively, TM8 and TM1 are potent and highly selective MAO-B inhibitors with little toxicity and good ROS scavenging abilities and it is suggested that both are attractive prospective candidates for the treatment of neurological disorders.

Keywords: chalcone; MAO-B; selectivity; reversibility; cytotoxicity; ROS; molecular dynamics

\section{Introduction}

Parkinson's disease (PD) is considered the second most common progressive neurodegenerative disorder in the elderly and is characterized by motor system disruption [1]. 
Over ten million people worldwide suffer from PD, which places an onerous responsibility on the medical community to develop an effective therapy [2]. This motor system disruption is caused by the extensive degeneration of the dopaminergic neurons, which leads dopamine (DA) depletion [3]. Current treatment strategies center on enhancing dopamine-like activities using monoamine oxidase (MAO)-B inhibitors, dopamine agonists, and catechol-O-methyltransferase (COMT) inhibitors, whereas developmental efforts appear to be focused on the identification of non-dopaminergic candidates like glutamate antagonists and anticholinergic drugs [4].

$\mathrm{MAO}$ is found in two isoforms, that is, MAO-A and MAO-B, and contains flavin adenine dinucleotide (FAD) as a cofactor. These isoforms share $70 \%$ amino acid sequence similarity and differ functionally in terms of their substrate specificities and inhibitor affinities [5]. Selective MAO-A and MAO-B inhibitors are considered important for the treatment of various neuropsychiatric and neurodegenerative disorders, respectively [6]. For example, the level of endogenous dopamine enhances the blockade of dopamine metabolism by selective MAO-B inhibition [7]. Numerous studies have documented that the formation of the 1-methyl-4-phenylpyridinium ion $\left(\mathrm{MPP}^{+}\right.$; a bioactive metabolite of 1-methyl-4-phenyl-1,2,3,6-tetrahydropyridine (MPTP)) is catalyzed by MAO-B, and that $\mathrm{MPP}^{+}$induces the neurotoxic effects associated with the pathophysiology of PD [8]. MPP interacts with mitochondrial complex 1 to induce neural toxicity in PD [9]. In view of the important roles played by MAO-B in neurodegenerative disorders, novel highly selective MAO-B inhibitors are of considerable interest [10].

A recent strategy used to produce highly selective MAO-B inhibitors included the installation of two aryl or heteroaryl rings on either end of the two to four carbons or nitrogencontaining spacer units, which include $\alpha-\beta$-unsaturated ketones, pyrazolines, enamides, and hydrazones [11-15]. The presence of a $\pi$-conjugated system with rotatable bonds in the linker can provide different orientations and facilitate interactions between designed scaffolds and the active site of MAO-B [16]. Chalcones are considered versatile scaffolds for selective MAO-B inhibitors. Recently, Guglielmi et al. predicted that chalcone derivatives are likely to exhibit selective human MAO-B (hMAO-B) inhibition based on results obtained using the free online tool SwissTargetPrediction (www.swisstargetprediction.ch (accessed on 10 October 2021)), which supports our previous experimental results [17,18].

Chalcones are $\alpha-\beta$ unsaturated ketones with three rotatable bonds and are endowed with a number of central nervous system (CNS) related activities, which include adenosine receptor antagonist and neuroprotective activities, ability to cross the blood-brain barrier (BBB), and inhibitions of MAO-B, acetylcholine esterase (AChE), transglutaminase, and $\beta$ amyloid plaques formation [19-22]. Numerous studies have demonstrated that substituent selection and the orientations of substituents on the chalcone $\mathrm{A}$ and/or $\mathrm{B}$ rings provide a promising means of producing reversible and selective inhibitors of hMAO-A and -B. Notably, the presence of lipophilic electron-donating groups (i.e., ethyl, methoxy, methyl, and dimethylamino, or halogens) at the same position on the $\mathbf{B}$ ring results in hMAO$B$ inhibition in the nanomolar range [23-26], whereas the introduction of methoxy at para-position of the A ring is associated with hMAO-B inhibitory activity [27-30]. The design strategy used in the present study involved the isosteric replacement of the A ring methoxy with a thiomethyl group and the introduction of different substituents on the B ring (Scheme 1).

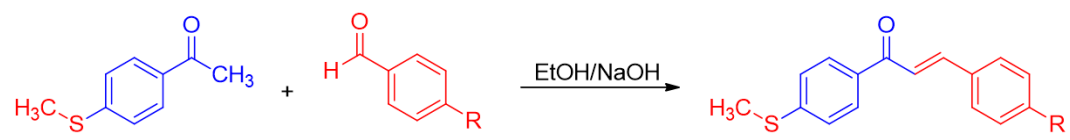

Scheme 1. Synthetic route to chalcone-thiomethyl ethers TM1-11.

To the best of our knowledge, the influence of isosteric replacement of the A-ring methoxy with a thiomethoxy group has not been previously reported to enhance hMAO-B inhibition (Figure 1). 


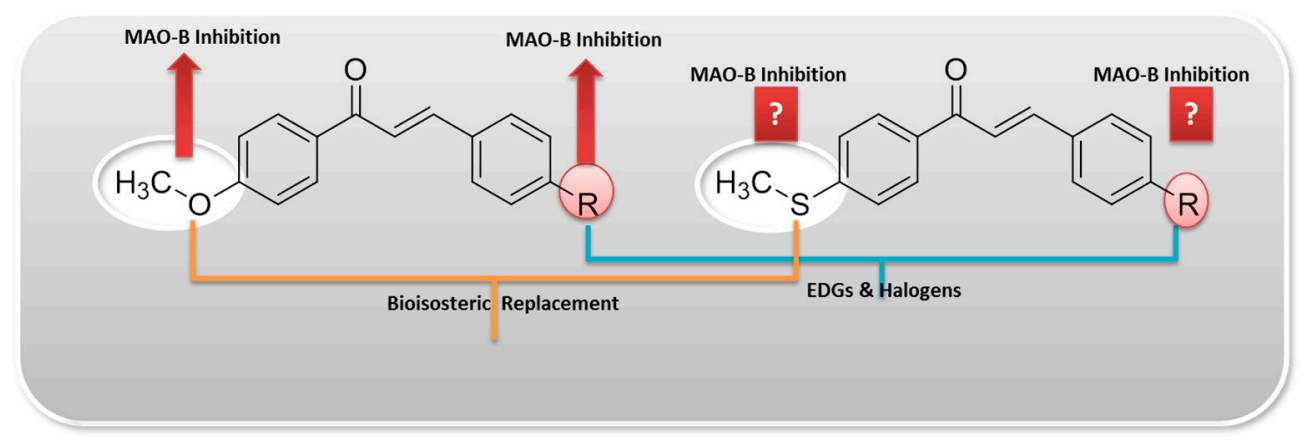

Figure 1. Design of chalcone-thioethers by bio-isosteric replacement for MAO-B inhibition.

We report a series of chalcone-thioether derivatives, which were prepared and evaluated for their MAO-A and MAO-B inhibitory activities, cytotoxicities, and effect on reactive oxygen species (ROS). Lead molecules were subjected to detailed molecular dynamics (MD) study to access their molecular mechanisms.

\section{Results}

\subsection{MAO Inhibition}

All eleven chalcone derivatives potently inhibited MAO-B at $10 \mu \mathrm{M}$; residual activities were $<15 \%$ (Table 1 ). Compound TM8 showed the highest inhibitory activity against MAO-B with an $\mathrm{IC}_{50}$ value of $0.010 \mu \mathrm{M}$, and TM1, TM2, TM7, and TM10 also exhibited potent inhibitory effects $\left(\mathrm{IC}_{50}=0.017,0.021,0.023\right.$ and $0.026 \mu \mathrm{M}$, respectively). The other six compounds had $\mathrm{IC}_{50}$ values $<0.15 \mu \mathrm{M}$. Interestingly, TM1, TM2, TM4, TM7, TM8, and TM10 were 3.7, 3.0, 1.1, 2.7, 6.3 and 2.4 times, respectively, more potent than the reference drug lazabemide. Similarly, TM1, TM2, and TM8 were 1.6, 1.3 and 2.8 times, respectively, more potent than pargyline. Compounds TM7 and TM10 were almost as potent as pargyline. Regarding the effects of substituents, the inhibitory potencies of these compounds followed the order $-\mathrm{Cl}>-\mathrm{H}>-\mathrm{OH}>-\mathrm{NO}_{2}>-\mathrm{F}$.

Table 1. Inhibitions of recombinant human MAO enzymes by Chalcone-thioethers ${ }^{\mathrm{a}}$.

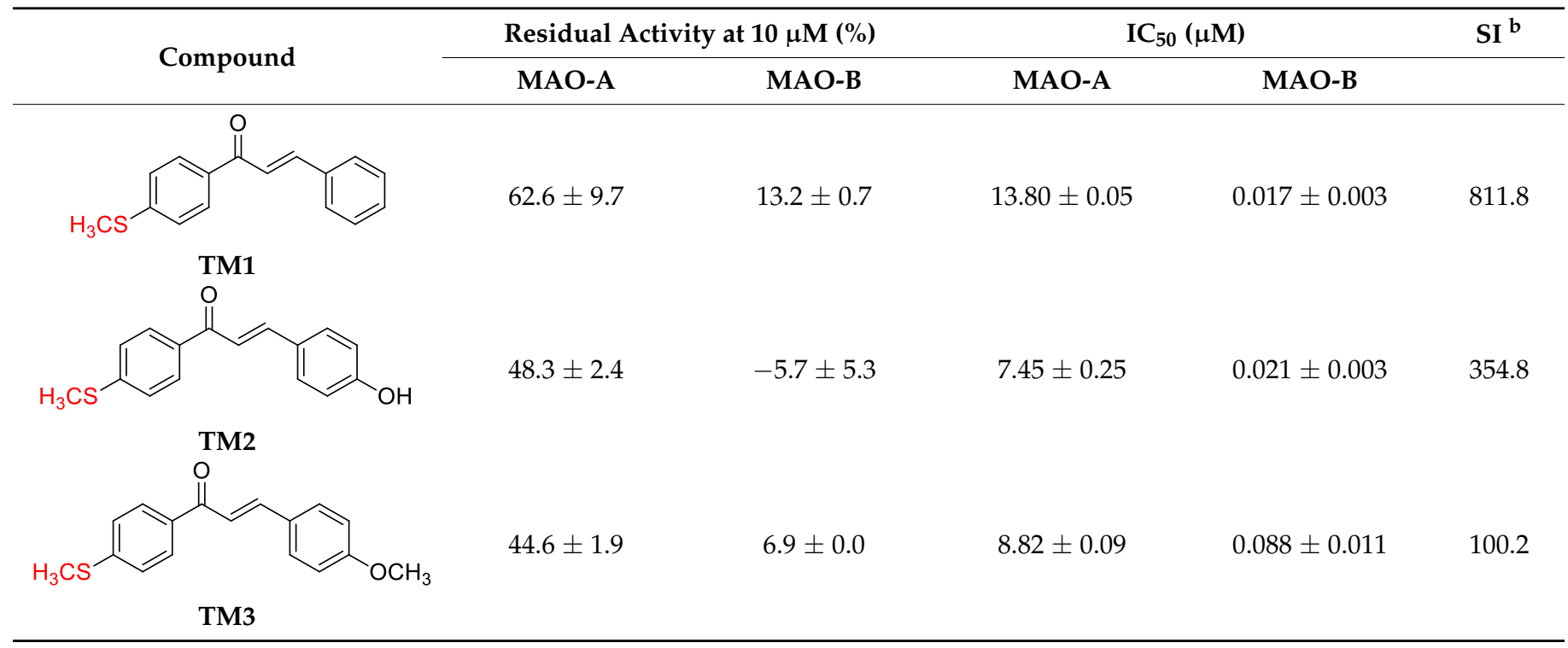


Table 1. Cont.

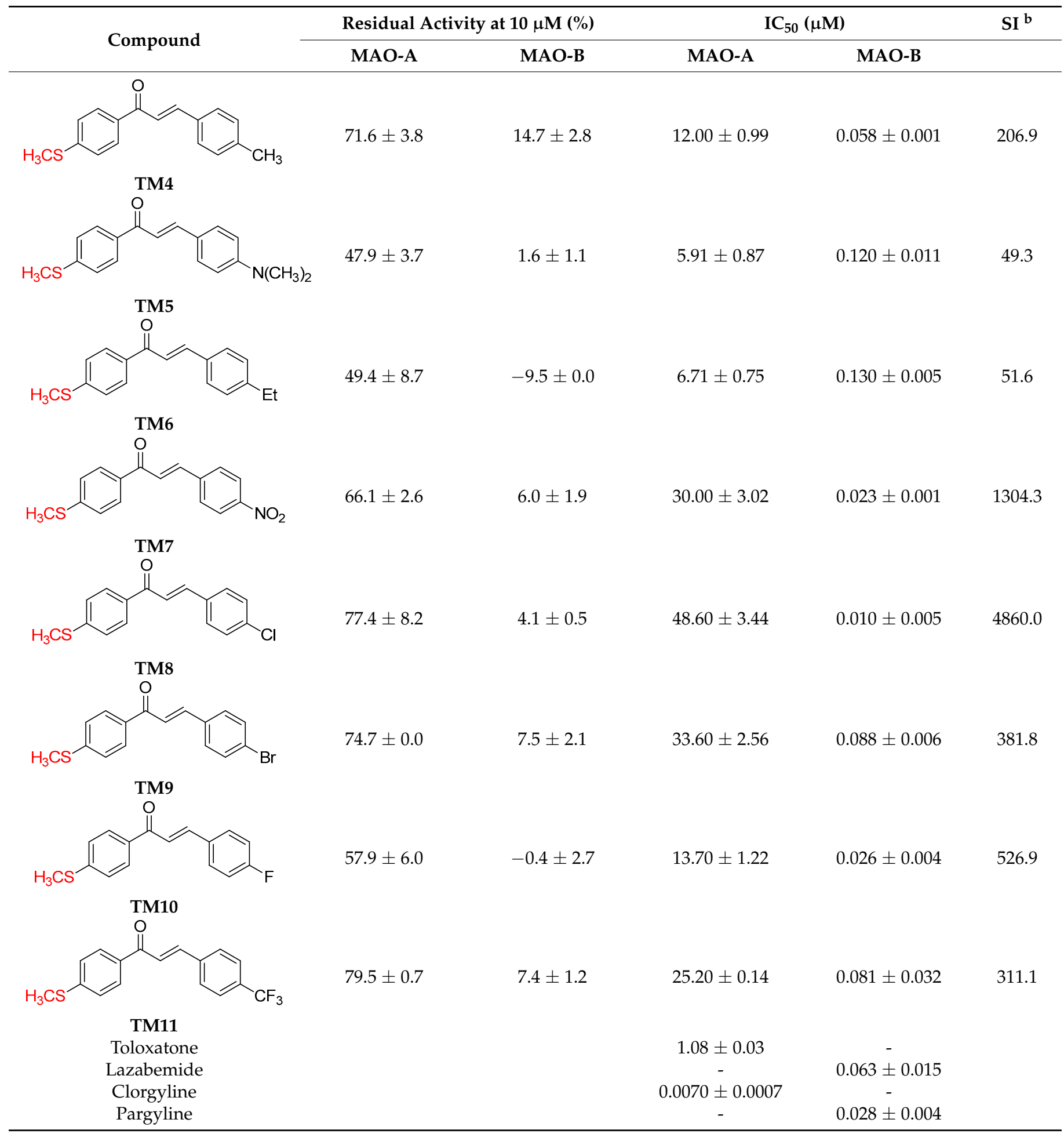

${ }^{a}$ Results are the means \pm standard errors of duplicate experiments. ${ }^{b}$ hMAO-B selectivity indices were calculated by dividing $\mathrm{IC}_{50}\left(\mathrm{hMAO}_{-}\right.$ A) by $\mathrm{IC}_{50}(\mathrm{hMAO}-\mathrm{B})$. Values for reference compounds were determined after preincubation with enzymes for $30 \mathrm{~min}$.

Compounds TM5, TM6, TM2, and TM3 at $10 \mu \mathrm{M}$ inhibited MAO-A with $\mathrm{IC}_{50}$ values of $5.91,6.71,7.45$, and $8.82 \mu \mathrm{M}$, respectively, whereas the other seven compounds had lesser effects (residual activities $>50 \%$ ) (Table 1 ). Interestingly, TM8 had a much higher selectivity index (SI; 4,860 ) for MAO-B than the other compounds. The next highest were compounds TM7 and TM1 with SI values of 1304 and 812, respectively. 


\subsection{Kinetics}

Kinetic studies on MAO-B inhibitions were performed on TM1 and TM8. LineweaverBurk plots and secondary plots showed that the lines intersected $y$-axes, thus indicating, TM1 and TM8 competitively inhibited MAO-B (Figure 2A,C). $\mathrm{K}_{\mathrm{i}}$ values were $0.011 \pm 0.001$ and $0.0031 \pm 0.0013 \mu \mathrm{M}$, respectively (Figure 2B,D). These results suggest that compounds TM1 and TM8 compete with the substrate at the active site of MAO-B.

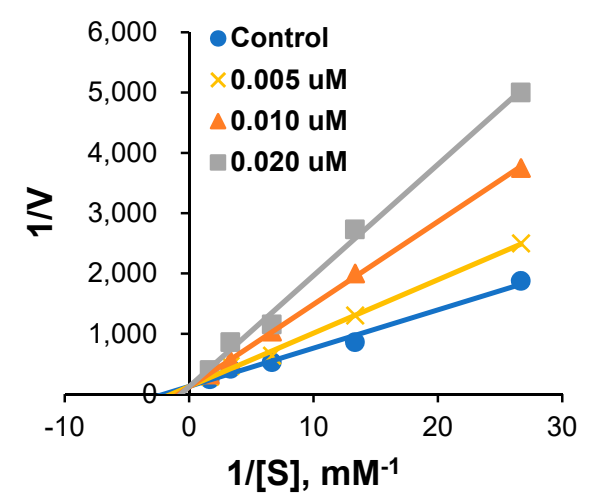

(A)

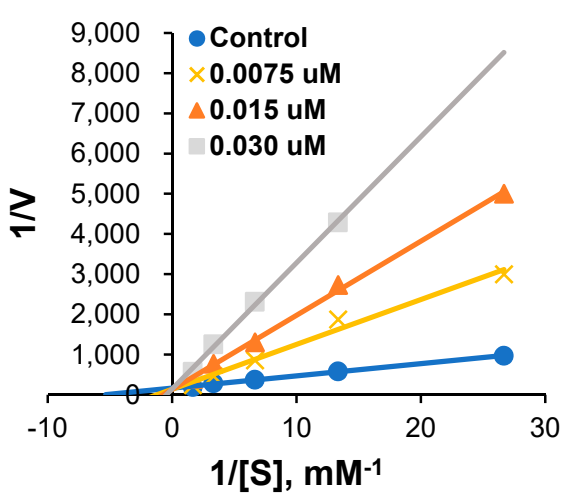

(C)

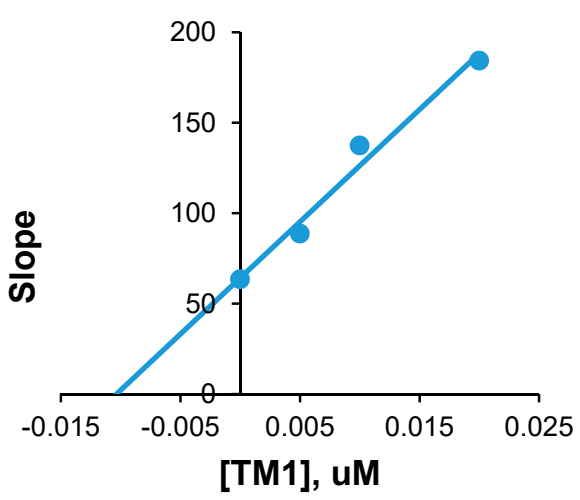

(B)

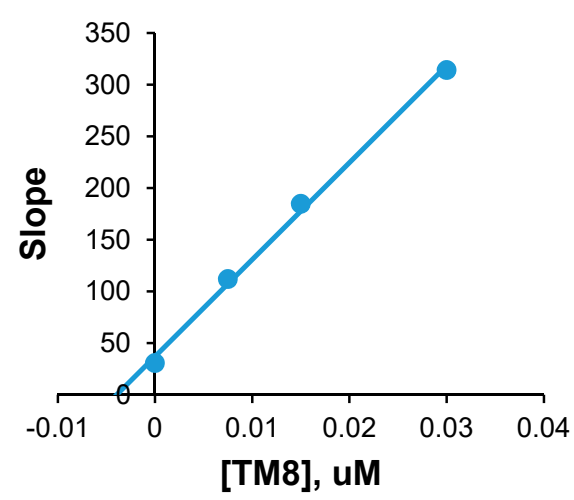

(D)

Figure 2. Lineweaver-Burk plots for MAO-B inhibition by TM1 and TM8 (A,C), and their respective secondary plots (B,D) of slopes vs. inhibitor concentrations.

\subsection{Reversibility}

MAO-B inhibition reversibility studies were conducted on compounds TM1 and TM8 using a dialysis-based method. MAO-B inhibition by TM1 was recovered by dialysis from $24.9 \%\left(A_{U}\right)$ to $68.1 \%\left(A_{D}\right)$, and inhibition by TM8 was recovered from $33.1 \%$ to $69.3 \%$. These recoveries were similar to that observed for the reference reversible lazabemide (from $16.6 \%$ to $74.9 \%$ ). Inhibition of MAO-B by pargyline (the reference irreversible inhibitor) was not recovered (from $24.7 \%$ to $31.4 \%$ ) (Figure 3). These results showed that compounds TM1 and TM8 were reversible MAO-B inhibitors.

\subsection{Cytotoxicity Evaluation}

African Green Monkey kidney cells (VERO cells) were used to evaluate the cytotoxic effects of TM1 and TM8. Cells were incubated with different doses $(1 \mu \mathrm{g} / \mathrm{mL}$ to $500 \mu \mathrm{g} / \mathrm{mL}$ ) of the two compounds for $48 \mathrm{~h}$, and relative cell viabilities were determined by MTT assay. Compound TM1 and TM8 reduced viabilities concentration-dependently (Figures $4 \mathrm{a}$ and $5 \mathrm{a})$; TM1 and TM8 treatments resulted in high viability $(>90 \%)$ at concentrations $<250$ and $<100 \mu \mathrm{g} / \mathrm{mL}$ (i.e., 983.1 and $346.3 \mu \mathrm{M}$ ), respectively, and the $\mathrm{IC}_{50}$ values were 241.6 and $116.2 \mu \mathrm{g} / \mathrm{mL}$ (i.e., 947.7 and $402.4 \mu \mathrm{M}$ ), respectively (Figures $4 \mathrm{~b}$ and $5 \mathrm{~b}$ ). Phase contrast microscopy showed that treatments above $\mathrm{IC}_{50}$ values resulted in membrane 
damage and reduced cell numbers. These results suggest that TM1 and TM8 are safe at low concentrations (Figures $4 \mathrm{c}$ and $5 \mathrm{c}$ ), and that at concentrations $>$ their $\mathrm{IC}_{50}$ values induced oxidative stress.

\section{Undialyzed}

\section{Dialyzed}

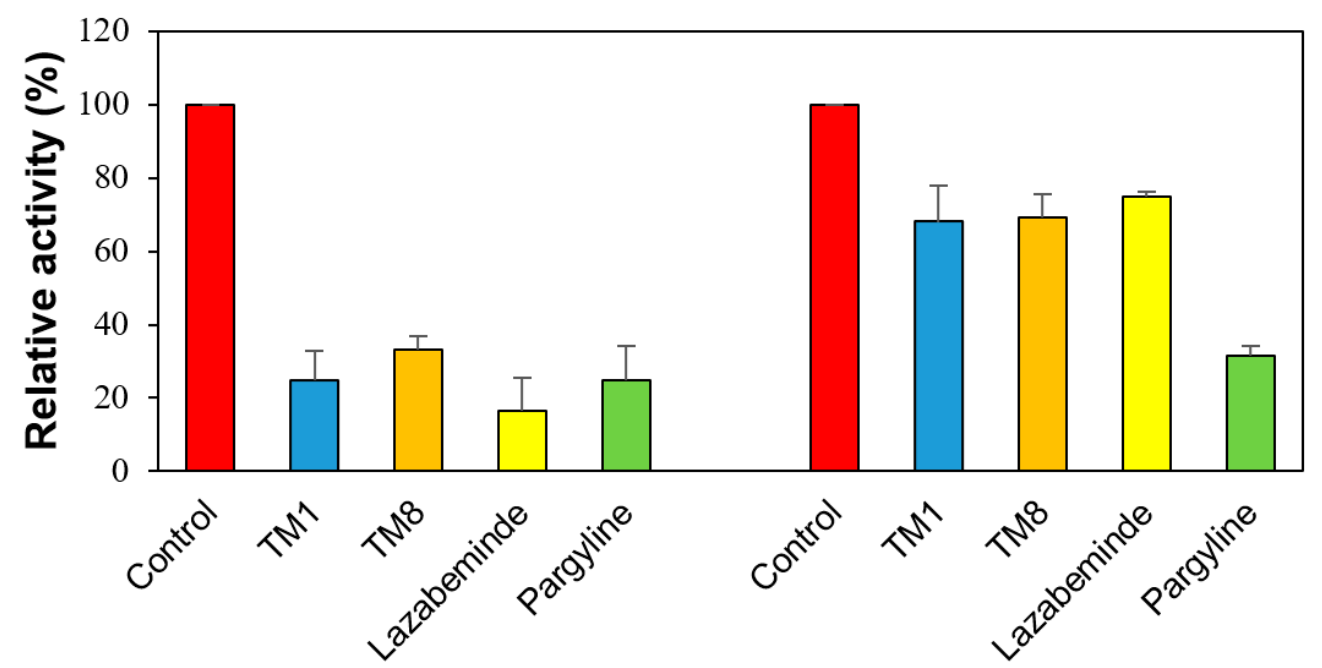

Figure 3. Dialysis recoveries of MAO-B inhibitions by TM1 and TM8.
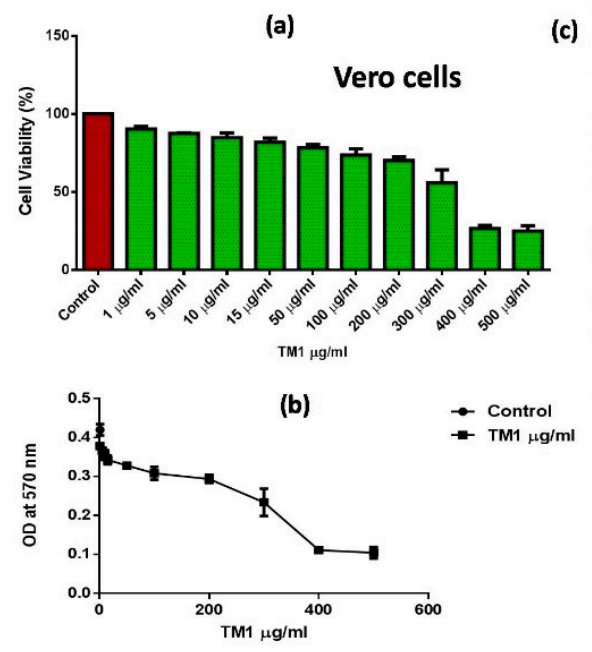

(c)

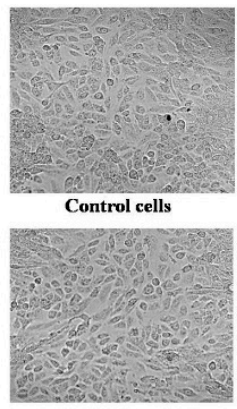

TM1 $50 \mu \mathrm{g} / \mathrm{ml}$

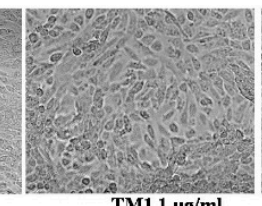

TM1 $1 \mu \mathrm{g} / \mathrm{ml}$
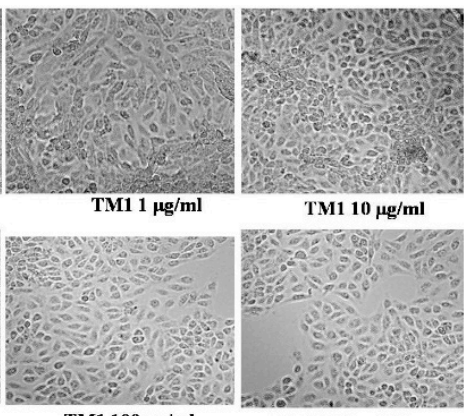

TM1 $100 \mu \mathrm{g} / \mathrm{ml}$

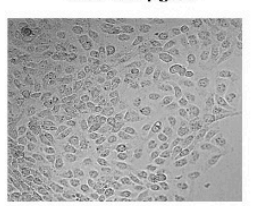

TM1 $500 \mu \mathrm{g} / \mathrm{ml}$

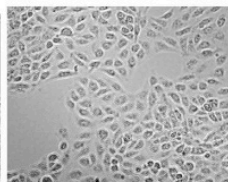

TM1 $300 \mu \mathrm{g} / \mathrm{ml}$

Figure 4. Effect of TM1 on Vero cell viability. (a) cell viability treated with TM1; (b) dose-response curve; (c) phase contrast microscope images of Vero cells treated with different concentrations of TM1. Cells were treated with TM1 for $48 \mathrm{~h}$ and cell viabilities were assessed by MTT assay as described in Section 4.

\subsection{ROS Assay}

ROS increase vulnerability to neuronal damage by causing oxidative damage in the brain during neurodegenerative diseases. When Vero cells were exposed to exogenous $\mathrm{H}_{2} \mathrm{O}_{2}$, intracellular ROS levels were elevated, but treatments with TM1 or TM8 at their $\mathrm{IC}_{50}$ values resulted in appreciably lower ROS levels (Figure 6a,b). 

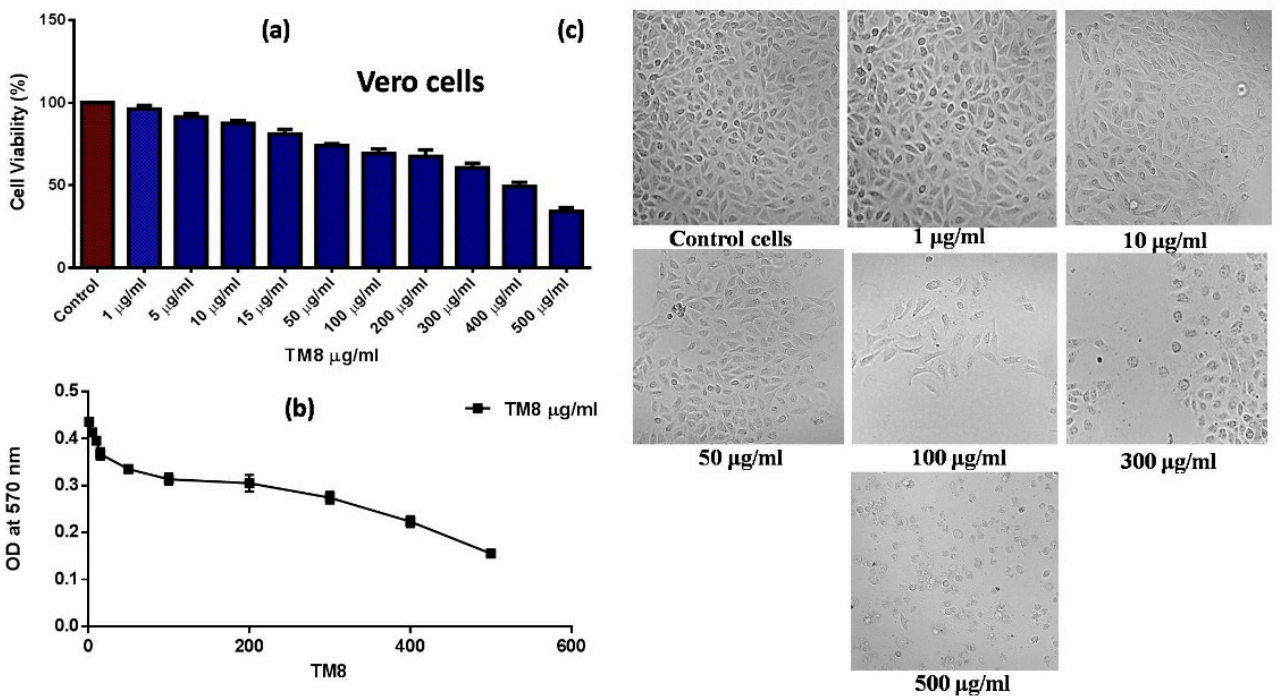

Figure 5. Effect of TM8 on Vero cell viability. (a) cell viability treated with TM8; (b) dose-response curve; (c) phase contrast microscope images of Vero cells treated with different concentrations of TM8. Cells were treated with TM8 for $48 \mathrm{~h}$ and cell viabilities were assessed by MTT assay as described in Section 4.

(a)

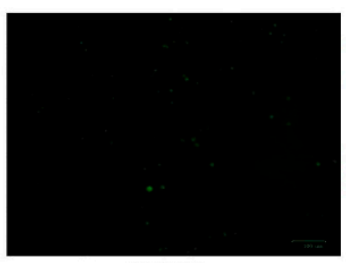

Control

(b)

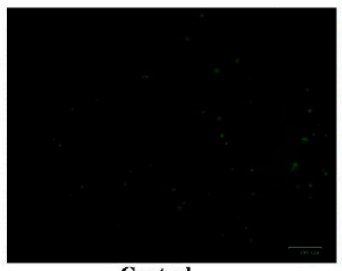

Control
Vero cells

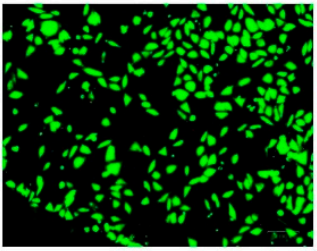

Cells treated with $\mathrm{H}_{2} \mathrm{O}_{2}$

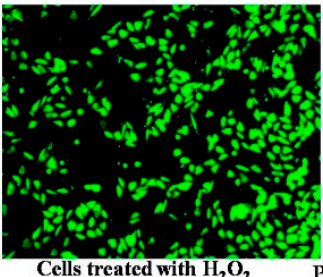

Cells treated with $\mathrm{H}_{2} \mathrm{O}_{2}$

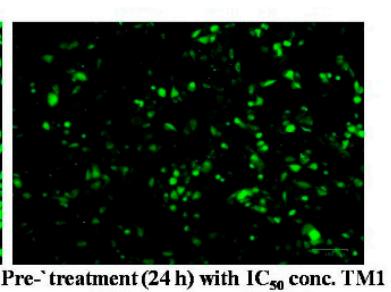

$+\mathrm{H}_{2} \mathrm{O}_{2}$ treatment $(10 \mathrm{~min})$

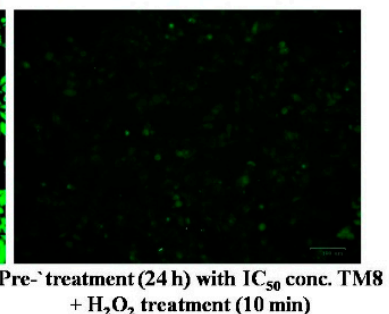

Figure 6. Effects of TM1 (a) and TM8 (b) on $\mathrm{H}_{2} \mathrm{O}_{2}$-induced ROS levels. Vero cells $\left(1 \times 10^{6}\right.$ cells $\left./ \mathrm{mL}\right)$ were pre-incubated with $100 \mu \mathrm{g} / \mathrm{mL}$ of $30 \% \mathrm{H}_{2} \mathrm{O}_{2}$ and ROS production was evaluated immediately as described in Section 4.

2.6. Blood-Brain Barrier (BBB) Permeation Study by Parallel Artificial Membrane Permeability Assay (PAMPA)

A highly effective permeability and high CNS bioavailability of thiomethane-containing chalcones were demonstrated with Pe ranges between 16.26 and $13.28 \times 10^{-6} \mathrm{~cm} / \mathrm{s}$ (Table 2) in the parallel artificial membrane permeability assay (PAMPA).

Table 2. BBB assay of lead molecules of chalcone-thioethers by PAMPA method.

\begin{tabular}{|c|c|c|c|}
\hline Compounds & $\begin{array}{l}\text { Bibliography } \\
\operatorname{Pe}\left(\times 10^{-6} \mathrm{~cm} \cdot \mathrm{s}^{-1}\right)\end{array}$ & $\begin{array}{c}\text { Experimental } \\
\operatorname{Pe}\left(\times 10^{-6} \mathrm{~cm} \cdot \mathrm{s}^{-1}\right)\end{array}$ & Prediction \\
\hline TM1 & & $15.54 \pm 0.33$ & CNS+ \\
\hline TM2 & & $13.28 \pm 0.80$ & CNS+ \\
\hline TM7 & & $15.53 \pm 0.71$ & CNS+ \\
\hline
\end{tabular}


Table 2. Cont.

\begin{tabular}{|c|c|c|c|}
\hline Compounds & $\begin{array}{l}\text { Bibliography [31] } \\
\operatorname{Pe}\left(\times 10^{-6} \mathrm{~cm} \cdot \mathrm{s}^{-1}\right)\end{array}$ & $\begin{array}{c}\text { Experimental } \\
\operatorname{Pe}\left(\times 10^{-6} \mathrm{~cm} \cdot \mathrm{s}^{-1}\right)\end{array}$ & Prediction \\
\hline TM8 & & $16.26 \pm 0.26$ & CNS+ \\
\hline TM10 & & $15.17 \pm 0.44$ & CNS+ \\
\hline Progesterone & 9.3 & $9.32 \pm 0.33$ & CNS+ \\
\hline Verapamil & 16.0 & $15.62 \pm 0.42$ & CNS+ \\
\hline Piroxicam & 2.5 & $2.44 \pm 0.26$ & $\mathrm{CNS} \pm$ \\
\hline Lomefloxacin & 1.1 & $1.22 \pm 0.02$ & CNS- \\
\hline Dopamine & 0.2 & $0.22 \pm 0.01$ & CNS- \\
\hline
\end{tabular}

CNS+ (high BBB permeation predicted): $\mathrm{Pe}\left(10^{-6} \mathrm{~cm} \cdot \mathrm{s}^{-1}\right)>4.00$; CNS - (low BBB permeation predicted): $\operatorname{Pe}\left(10^{-6} \mathrm{~cm} \cdot \mathrm{s}^{-1}\right)<2.00$; CNS \pm (BBB permeation uncertain): Pe $\left(10^{-6} \mathrm{~cm} \cdot \mathrm{s}^{-1}\right)$ from 2.00 to 4.00.

\subsection{Inhibitor-Induced Binding Pocket Dynamics}

Binding pocket residues of MAO-B exhibited average root mean square deviations (RMSDs), of 1.77, 1.81, 1.29, 1.64 and $1.81 \AA$ for TM1, TM2, TM7, TM8 and TM10, respectively (Figure 7), suggesting relatively stable conformations since average values were below $2 \AA$. An average RMSD of $2.59 \AA$ was estimated for unbound MAO-B, which suggested a relatively unstable conformation. According to Luque and Freire in 2000 [19], a stable binding pocket conformation provides optimum binding affinity for small ligands. We assessed the rigidity or compactness of the binding pocket residues by estimating their conformational changes within the binding pocket of MAO-B mediated by TM1, TM2, TM7, TM8 and TM10, which altered the overall structure and function of MAO-B radii of gyration over a $250 \mathrm{~ns}$ MD simulation period. Relatively stable conformations were observed, and binding pocket residues in inhibitor-bound MAO-B complexes were more compact/rigid with average radii of gyration (ROGs) of 12.39, 12.56, 12.55, 12.57 and $12.33 \AA$ for TM1, TM2, TM7, TM8 and TM10, respectively. Unbound MAO-B binding pocket residues exhibited a relatively higher average ROG of $12.65 \AA$, which suggest that bindings of TM1, TM2, TM7, TM8 and TM10 enhanced binding pocket stability. An assessment of the solvent surface exposure of binding pocking residues also provided insights into the conformational dynamics of the binding pocket after inhibitor binding $[14,20,21]$. As shown in Figure 8, binding pocket residues in inhibitor-MAO-B complexes exhibited lower average solvent accessible surface area (SASA) values of 235.63, 391.84, 249.47, 330.29 and $184.76 \AA^{2}$ for TM1, TM2, TM7, TM8 and TM10, respectively, while the unbound conformation had an SASA of $491.38 \AA^{2}$. This observation was in line with ROG results and indicated $\mathrm{MAO}-\mathrm{B} / \mathrm{TM}$ series binding resulted in greater structural compactness and inward folding of the binding pocket, which also suggests enhanced ligand binding and stability. 


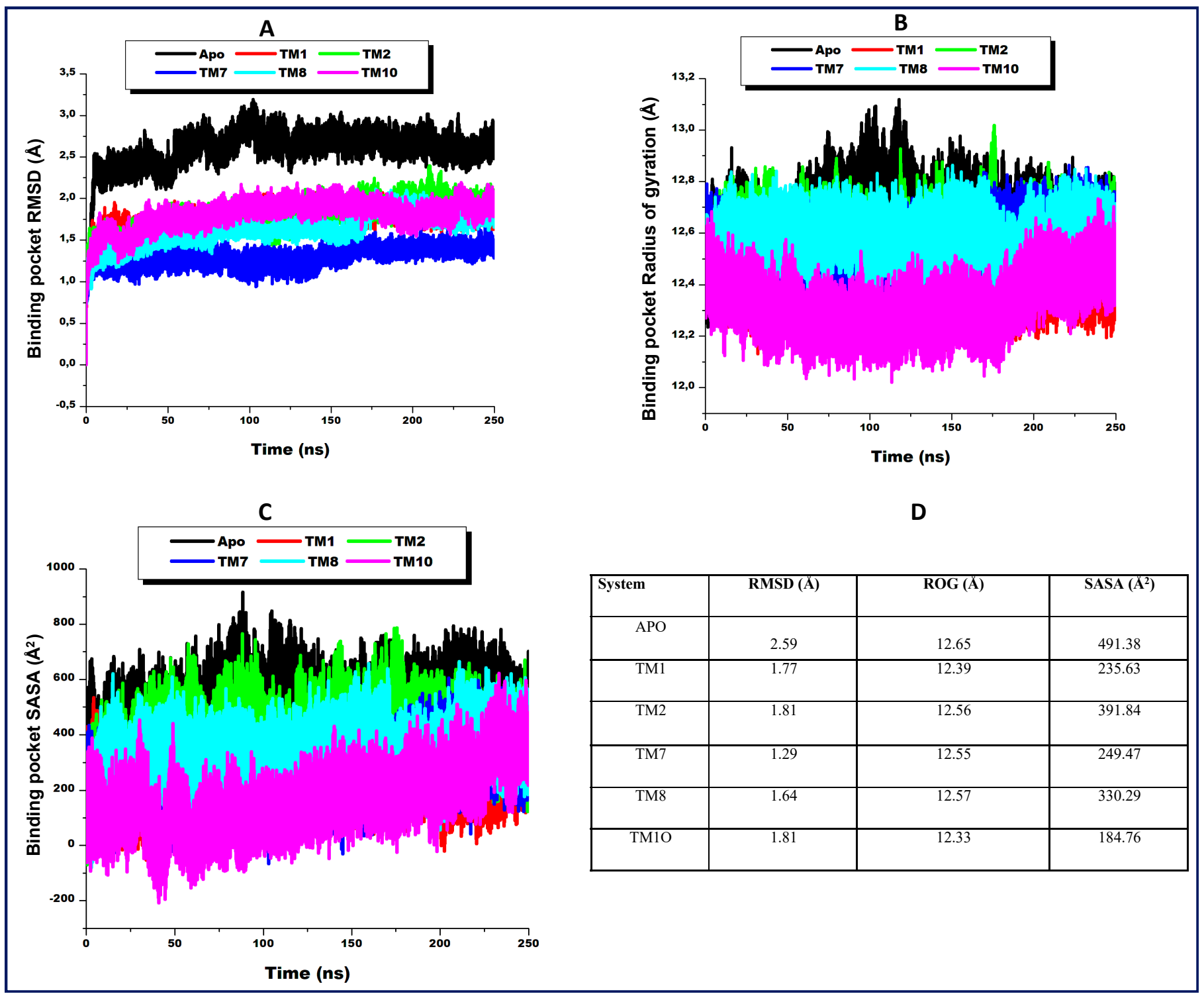

Figure 7. Comparative RMSD plots (A), comparative radii of gyration plots (B), and comparative SASA plots (C) of the binding site residues of free MAO-B (black) and MAO-B bound to TM1 (red), TM2 (green), TM7 (blue), TM8 (cyan), or TM10 (magenta), and average RMSD, ROG, and SASA values of MAO-B binding site residues (D). 

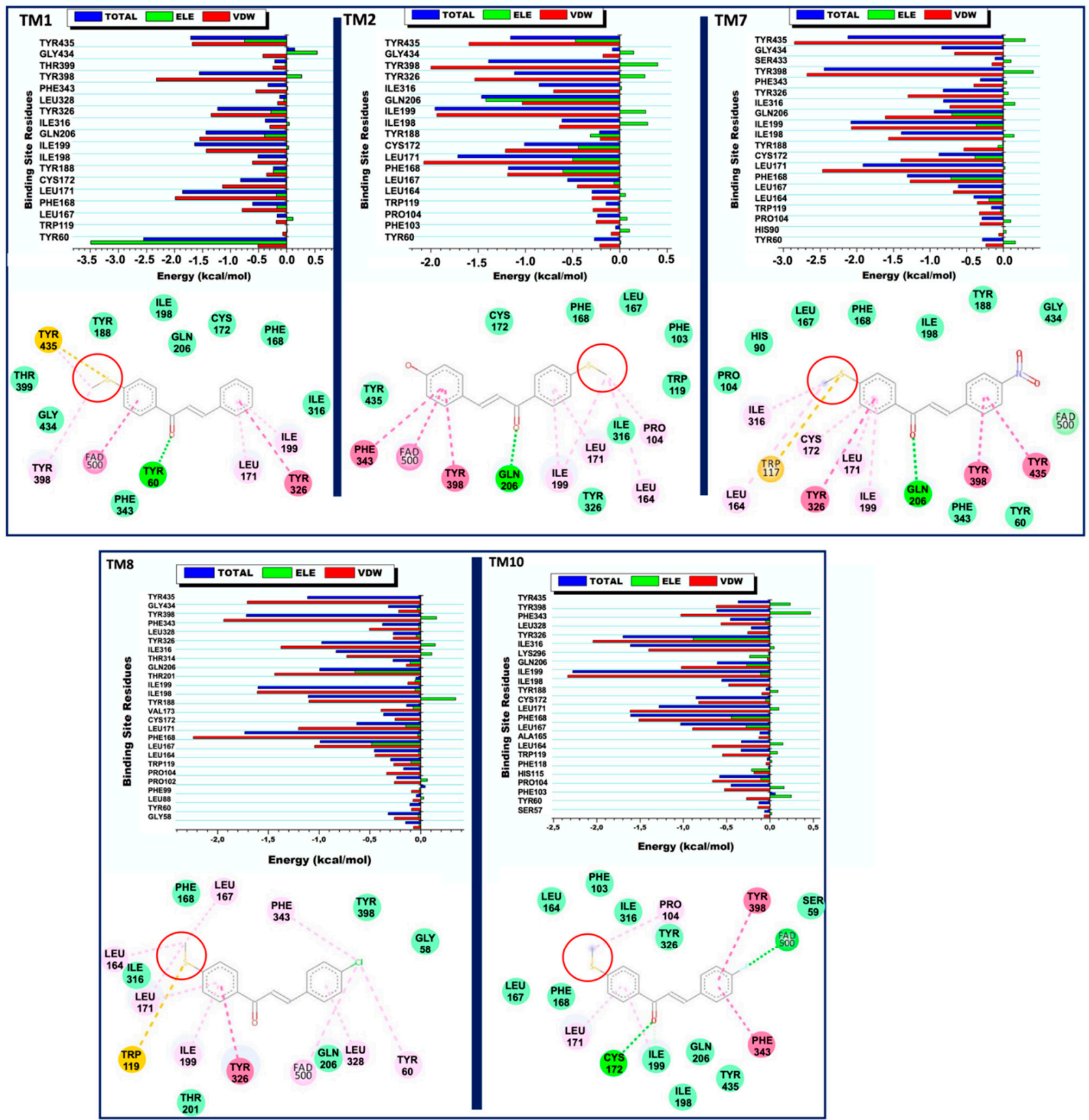

Pi-Sigma

Conventional hydrogen bond

van der Waals

Pi-Alkyl

Pi-Pi Stacked

Figure 8. Per-residue energy contributions of interacting residues at the MAO-B inhibitor binding site after TM1, TM2, TM7, TM8 or TM10 binding. Corresponding residue interactions are also shown. Inserts highlight the interaction dynamics of the SCH3 moeity of each compound.

\section{Discussion}

Chalcones provide a simple framework with broad-spectrum biological activities and are accessible by Claisen-Schmidt condensation. The aldehyde used becomes the $\mathbf{B}$ ring of the chalcone, whereas the acetophenone used becomes the $\mathbf{A}$ ring. The $\alpha, \beta$-unsaturated ketone moiety of chalcones is considered a Michael acceptor and may be involved in the signaling of many biochemical pathways. The presence of olefinic linkage introduces the possibility of cis- and trans-isomers, but the more thermodynamically stable trans-form is invariably produced. The presence of electron-donating and -withdrawing groups on 
the phenyl ring of chalcones greatly influences the electron density on the enone moiety and the orientations of the three rotatable bonds of the chalcone framework. These unique features enable this simple framework to interact with enzyme targets, preferably those with hydrophobic pockets.

Our structure-activity relationship (SAR) investigation of the designed chalconethioethers showed reasonable relations with observed inhibitory effects. In the 11 chalcone derivatives, the thioether (-SMe) group was located on the A ring and other alterations were made by placing various substituents at the para-position on the ring B. Compound TM1 (the parent compound) had no substituent at the para-position but had excellent MAO-B inhibitory effect with an $\mathrm{IC}_{50}$ value of $0.017 \pm 0.0026 \mu \mathrm{M}$ and an SI of 811.8 . The $\mathrm{K}_{\mathrm{i}}$ value of TM1 for MAO-B $(0.011 \pm 0.001 \mu \mathrm{M})$ is much potent than the unsubstituted methoxylated chalcone $(\mathbf{C} 1)$ previously reported by our group $(0.70 \pm 0.05 \mu \mathrm{M})$ [30]. This crucial observation clearly showed that bio-isosteric replacement with thioether group on the para position of phenyl ring $\mathbf{A}$ in the chalcone framework resulted in pronounced MAO$\mathbf{B}$ inhibitory activities. The introduction of chlorine atom on the para position of ring $\mathbf{B}$ with thioether group on the A ring resulted highly potent MAO-B inhibition $\left(\mathrm{K}_{\mathrm{i}}=0.0031 \mu \mathrm{M}\right)$ (Figure 9).

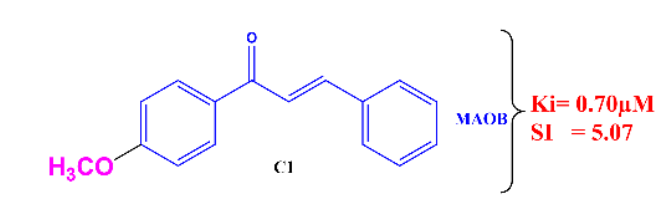

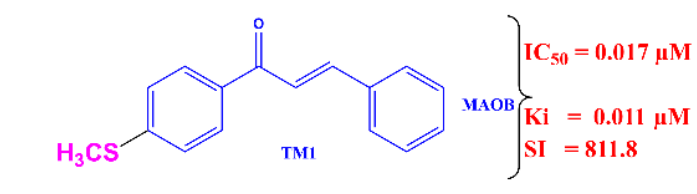

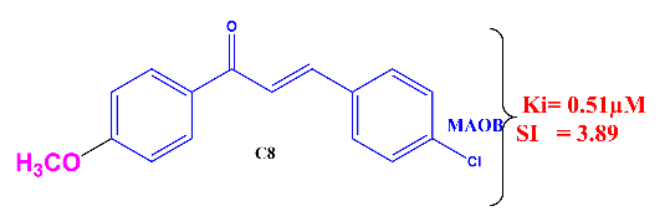<smiles>CSc1ccc(C(=O)/C=C/c2ccc(Cl)cc2)cc1</smiles>

Figure 9. Influence of bio-isosteric replacement with respect to MAO-B inhibition.

When $-\mathrm{NMe}_{2}$ (a strong election-releasing group (ERG)) was introduced, resulting TM5 showed a 7-fold fall in inhibitory activity and a 10-fold reduction in selectivity $\left(0.12 \pm 0.01 \mu \mathrm{M}\right.$ and 49.3 , respectively). Similar results were observed when $-\mathrm{CH}_{2} \mathrm{CH}_{3}$ (a weak ERG) was introduced to produce TM6 (Table 1), which was ascribed to its bulkiness. The results were ascertained by introduction of small but strong and relatively week electron-releasing groups such as $-\mathrm{OH},-\mathrm{OMe}$, and -Me. The -OMe (a strong ERG) increased inhibition and selectivity with respect to TM5 and TM6 $\left(\mathrm{IC}_{50}=0.088 \pm 0.011 \mu \mathrm{M}\right.$ and 100.2). Of the ERG introduced, those with a weak ERG (e.g., $-\mathrm{Me}$ ), except -OH, increased inhibition and selectivity $\left(\mathrm{IC}_{50}=0.058 \pm 0.001 \mu \mathrm{M}\right.$ and 206.9 , respectively). The strong ERG -OH, TM2, had an inhibitory effect $\left(\mathrm{IC}_{50}=0.021 \pm 0.003 \mu \mathrm{M}\right)$ similar to the parent compound TM1, but considerably less selectivity, which may have been due to hydrogen bonding. Generally, ERGs had marked MAO-B inhibitory effects as compared with the parent compound TM1. The effects of electron-withdrawing groups (EWG) on chalconethioethers on MAO-B inhibitory activity were also investigated. The introduction of $-\mathrm{NO}_{2}$ (the strongest EWG) in TM7 resulted in inhibitory activity $\left(\mathrm{IC}_{50}=0.023 \pm 0.001 \mu \mathrm{M}\right)$ similar to the parent compound TM1 but improved selectivity $(1,304.3)$, whereas the introduction of $-\mathrm{CF}_{3}$ (a weak EWG) in TM11 caused a considerable drop in inhibitory activity and selectivity $\left(\mathrm{IC}_{50}=0.081 \pm 0.032 \mu \mathrm{M}\right.$ and 311.1, respectively). Other halogens (also EWGs) such as $-\mathrm{F},-\mathrm{Cl}$, and $-\mathrm{Br}$ had effects similar to $\mathrm{TM10}\left(\mathrm{IC}_{50}=0.026 \pm 0.004 \mu \mathrm{M}\right)$ and a drop $(0.088 \pm 0.006 \mu \mathrm{M})$ in MAO-B inhibition effect with respect to the parent compound, except $-\mathrm{Cl}$ (TM8). In addition, a considerable drop in selectivity was also observed for these groups. The $-\mathrm{Cl}$ was a more effective pharmacophore than other halogens and EWGs. TM8 containing- $\mathrm{Cl}$ had the highest MAO-B inhibitory activity $\left(\mathrm{IC}_{50}=0.010 \pm 0.005 \mu \mathrm{M}\right)$ and selectivity (4860.0) and had 6.3 and 2.8 times more inhibitory activity than the reference drugs lazabemide and pargyline, respectively. In contrast, strong EWGs such as 
$-\mathrm{OH},-\mathrm{OMe},-\mathrm{NMe}_{2}$, and -Et exhibited better MAO-A inhibitory effects than the parent compound and other EWGs but had far lower inhibitory effects than the reference drugs (Table 1). SAR in this study can be summarized as shown in Figure 10.

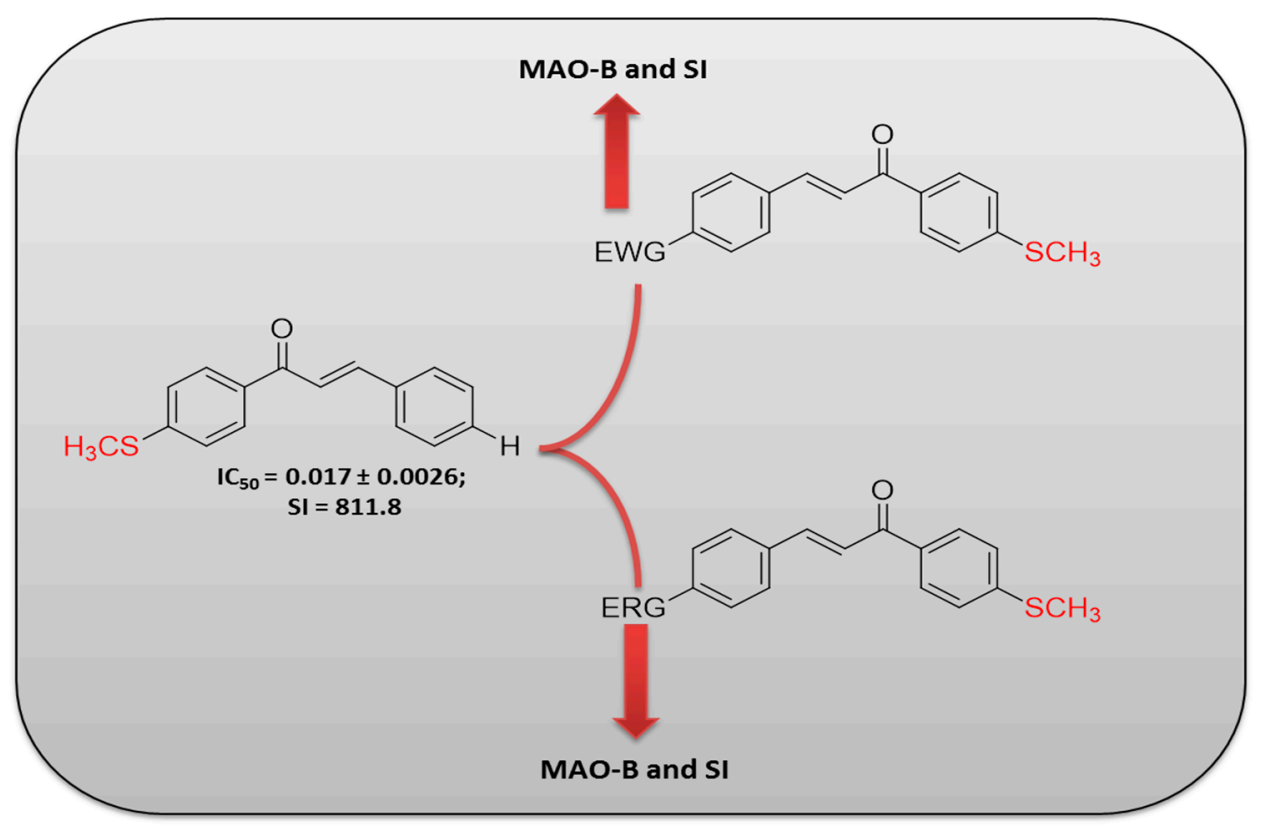

Figure 10. SARs of chalcone-thioethers with respect to MAO-B inhibition.

Previously, our group developed some methoxylated chalcones as selective MAO-B inhibitors and the lead molecule showed effective inhibitory activity ( $\left.\mathrm{IC}_{50}=0.29 \pm 0.01 \mu \mathrm{M}\right)$ [30] In current study, the bioisosteric replacement of methoxy group into thiomethyl group showed significantly increased MAO-B inhibition. In another recent study of Shalaby et al., compound (E)-3-(3-bromophenyl)-1-(4-(methylthio)phenyl)prop-2-en-1-one exhibited efficient MAO-B inhibition with $\mathrm{IC}_{50}=0.19 \pm 0.01 \mu \mathrm{M}$ [25]. It is noteworthy that the replacement of methoxy chalcones to thiomethyl resulted in enhancement of overall MAO-B inhibitory profiles with high SI values. Interestingly, the analogues tested resulted in potent inhibitory activities in nanomolar ranges towards MAO-B inhibition.

Toxicity assessment were conducted using Vero cells, which are commonly used to assess viability and lethality at a cellular level. We found that more than $90 \%$ of cells treated with TM1 or TM8 at effective concentrations remained viable. However, extensive blebbing and membrane damage were observed when cells were treated at high concentrations. Our cell viability and phase contrast microscopy studies showed that TM1 is a safer proposition than TM8. Furthermore, our investigation of the inhibitory effects of TM1 and TM8 on ROS, which are known to play significant roles in the pathogeneses of neurodegenerative diseases and to cause cell death or oxidative stress (OS) when present in excess, showed TM1 and TM8 at their $\mathrm{IC}_{50}$ levels mitigated $\mathrm{H}_{2} \mathrm{O}_{2}$-induced increases in ROS levels.

MD simulation provides a means of exploring the structural changes and functions caused by the binding of small molecules and has been used to investigate associations between protein activities and structural dynamics. By comparing protein conformations in binding pockets before and after ligand binding, we were able to identify inhibitor-induced conformational changes associated with inhibition of MAO-B. To observe these conformational changes, we employed MD simulation metrics, that is, RMSD, ROG, and SASA.

Having established that compound bindings induced conformational changes that might favor binding affinity, we estimated the binding free energy for compound/MAO-B complexes using experimentally determined $\mathrm{IC}_{50}$ values. Using the MM/PBSA approach, we calculated the binding energies of the compounds (Table 1). As shown by the table, the compounds exhibited favorable total binding energies, which was in line with our experimental data. Total binding energies for TM1, TM2, TM7, TM8, and TM10 were 
$-40.83 \pm 2.63,-34.40 \pm 2.63,-47.02 \pm 2.65,-37.02 \pm 3.05$, and $-35.14 \pm 2.81 \mathrm{kcal} / \mathrm{mol}$, respectively, which suggested that these chalcone derivatives engage in favorable interactions with the active site residues of MAO-B. Though all the compounds exhibited binding in accord with their free total binding energies, TM7/MAO-B complex had the highest free total binding energy $(-47.02 \pm 2.65 \mathrm{kcal} / \mathrm{mol})$, which was attributed to greater Van der Waals (VDW) forces and electrostatic (ELE) interactions. Overall, it was noticed that VDW interactions $(\triangle \mathrm{EvdW})$ were important for ligand binding, whereas the favorable ELE interactions ( $\Delta$ Eele) compensated for unfavorable polar solvation energies.

Intermolecular interactions between compounds and binding site residues influence the stabilities of the complexes formed. The total binding free energies of the compounds TM1 and TM8 were decomposed into individual residue-based contributions using the MM/PBSA method. The VDW and ELE energy contributions were expressed as percentages of total binding free energies to determine which residues and energy constituents had the greatest effects on total energy. As shown in Figure 8, the top three residues that contributed the most to the binding of TM1 against MAO-B were TYR60 $(-2.55 \mathrm{kcal} / \mathrm{mol})$, LEU171 $(-1.85 \mathrm{kcal} / \mathrm{mol})$, and TYR435 $(-1.71 \mathrm{kcal} / \mathrm{mol})$; that to the binding of TM2 were ILE199 $(-1.95 \mathrm{kcal} / \mathrm{mol})$, LEU171 $(-1.71 \mathrm{kcal} / \mathrm{mol})$, and GLN206 $(-1.46 \mathrm{kcal} / \mathrm{mol})$; that to the binding of TM7 were TYR398 $(-2.44 \mathrm{kcal} / \mathrm{mol})$, TYR435 $(-2.12 \mathrm{kcal} / \mathrm{mol})$, and ILE199 $(-2.0 \mathrm{kcal} / \mathrm{mol})$; that to the binding of TM8 were LEU171 $(-1.73 \mathrm{kcal} / \mathrm{mol})$, TYR398 (-1.71 kcal $/ \mathrm{mol})$ and ILE199 $(-1.60 \mathrm{kcal} / \mathrm{mol})$; and that to the binding of TM10 were ILE199 $(-2.27 \mathrm{kcal} / \mathrm{mol})$, TYR326 $(-1.69 \mathrm{kcal} / \mathrm{mol})$, and ILE316 $(-1.61 \mathrm{kcal} / \mathrm{mol})$. Although unfavorable ELE interactions were observed in interaction profiles, as shown by the plots in Figure 8, these would have had little effects on total binding due to the cumulative effects of ELE and VDW energy contributions. Particular focus on the SCH3 group, as highlighted in Figure 8, showed the formation of high-affinity interactions with $\mathrm{MAO}-\mathrm{B}$, relative to other moieties thus indicating its cruciality to the binding mechanism of synthesized compounds. Specific interactions of the SCH3 group in each compound included; TM1 ( $\pi$-sigma and $\pi$-alkyl with TYR435, $\pi$-alkyl with TYR398), TM2 ( $\pi$-alkyl with ILE199, LEU164 and PRO104), TM7 ( $\pi$-sigma with TRP117 and $\pi$-alkyl with TRP117 and TRP316), TM8 ( $\pi$-sigma with TRP119 and $\pi$-alkyl with LEU164, LEU171, LEU167) and TM10 ( $\pi$-alkyl with PRO104). These SCH3-mediated high-affinity interactions could contribute to stability and the overall total binding affinity of each compound.

Study of the residues involved in binding revealed that the comparatively high binding affinity of TM7 could be attributed to relatively high binding energy contributions. Furthermore, these cumulative per-residue energy contributions might explain the MAO-B inhibitory effects of TM1, TM2, TM7, TM8, and TM10. Also, these estimations support predictions based on binding free energies.

\section{Materials and Methods}

\subsection{Synthesis}

Chalcone-thioethers (TM1-11) were synthesized using base-catalyzed Claisen-Schmidt condensation between various para-substituted aromatic aldehydes and 4-thiomethyl acetophenone. Target compounds were produced by stirring ethanol solutions of $0.01 \mathrm{M}$ of 4-thiomethylacetophenone with appropriate aromatic aldehydes containing $40 \% \mathrm{NaOH}$ solution for 8-10 h [32]. The resulting reaction mixtures were poured into ice-cold water, and the products were collected, washed thoroughly with water, and recrystallized from ethanol. Spectral data were provided in Supplementary Materials.

\subsection{Biological Evaluations}

\subsubsection{MAO Enzyme Inhibition}

MAO-A activity was estimated continuously for $20 \mathrm{~min}$ at $316 \mathrm{~nm}$ using $0.06 \mathrm{mM}$ kynuramine as substrate, whereas MAO-B activity was measured for $30 \mathrm{~min}$ at $250 \mathrm{~nm}$ using $0.3 \mathrm{mM}$ benzylamine as substrate, as described previously [33]. MAO activity assays were performed using recombinant human MAO-A or MAO-B. 


\subsubsection{Kinetics Study}

MAO-A activities were estimated after exposing it to inhibitors at $10.0 \mu \mathrm{M}$, whereas MAO-B activities were estimated at an inhibitor concentration of $1.0 \mu \mathrm{M}$. $\mathrm{IC}_{50}$ values were determined by measuring residual enzyme activities. Toloxatone and lazabemide were used as reference reversible inhibitors for MAO-A and MAO-B, respectively, and clorgyline and pargyline as reference irreversible inhibitors. $K_{i}$ values and inhibitor types were determined by kinetic testing, as previously described [34]. Kinetic tests were performed at 5 different substrate concentrations and inhibitor concentrations of $0, \sim 1 / 2 \times \mathrm{IC}_{50}, \mathrm{IC}_{50}$, and $2 \times \mathrm{IC}_{50}$ values. Lineweaver-Burk plots $(\mathrm{LB})$ and their secondary plots were used to determine $K_{i}$ values and inhibitor types.

\subsubsection{Reversibility Studies}

The reversibilities of MAO-B inhibitions by TM1 and TM8 were assessed by dialysis. Test compounds were preincubated with MAO-B at $0.15 \mu \mathrm{M}$ for $30 \mathrm{~min}$, as described previously [35]. MAO-B was also preincubated with the positive controls for the experiment; lazabemide (a reference reversible $\mathrm{MAO}-\mathrm{B}$ inhibitor) or pargyline (a reference irreversible MAO-B inhibitor) at 0.20 and $0.30 \mu \mathrm{M}$, respectively. Reversibility patterns were determined by comparing the activities of dialyzed $\left(\mathrm{A}_{\mathrm{D}}\right)$ and undialyzed $\left(\mathrm{A}_{U}\right)$ samples.

\subsubsection{Cytotoxicity and ROS Assays}

The cytotoxicities and ROS quenching abilities of the two lead compounds (TM1 and TM8) were evaluated as previously described [36,37].

\subsubsection{BBB Study by PAMPA Method}

The CNS bioavailability of the lead candidates was further ascertained by PAMPA method [31].

\subsection{Computational Studies}

\subsubsection{System Preparation}

Initial coordinates of MAO-B (PDB ID: 6RKB) were selected [38]. The structure of MAO-B consists of two identical chains, A and B, which forms a MAO-B homodimer. Each chain contains a cofactor FAD, an inhibitor, water, and non-standard residues. Chain B was removed together with the water and non-standard residues using UCSF Chimera [39], and the 'cleaned' chain A was then saved in pdb format. The 2D structures of the compounds TM1, TM2, TM7, TM8 and TM10 were drawn using Marvin Sketch and optimized with Avogadro to generate 3D structures. Using UCSF Chimera, hydrogen atoms and Gasteiger charges were added and results were saved in mol2 format for molecular docking at the active site of 'cleaned' MAO-B.

\subsubsection{Molecular Docking}

Docking was performed using the AutoDock Vina module incorporated into UCSF Chimera [40]. A grid box with coordinates of 51.3568, 154.894 and 29.7124, and $x, y$, and $z$ dimensions of $23.009,22.8623$, and 26.0373 was used to define the location of the MAO-B binding site. Docked results generated were saved in pdbqt format. Conformations with best binding scores were selected and saved.

\subsubsection{Molecular Dynamics Simulation}

Six systems (five complexes bound with the inhibitors and unbound MAO-B (Apo)) were set up for molecular simulation using the GPU version incorporated in AMBER18 [41]. Forcefield FF14SB was used to define the systems. The ANTECHAMBER module was used to add atomic partial charges to ligands using the Restrained Electrostatic Potential (RESP) and the General Amber Force Field (GAFF) protocols [42]. 


\section{Conclusions}

The current study demonstrated a series of thiomethyl group containing chalcones as potent and selective class of MAO-B inhibitors. In conclusion, TM8 and TM1 were found to be reversible, selective, and competitive inhibitors of MAO-B with $\mathrm{K}_{\mathrm{i}}$ values of $0.0031 \pm 0.0013$ and $0.011 \pm 0.001 \mu \mathrm{M}$, respectively. The isosteric replacement of the $\mathbf{A}$ ring methoxy- with a thiomethyl- group and the introduction of different substituents on the B ring showed good MAO-B inhibition. Moreover, TM8 and TM1 were found to be safe as analyzed by an in vitro toxicity study. Additionally, the prooxidant and antioxidant levels can be retained by TM8 and TM1. Our findings show that TM8 and TM1 are selective inhibitors of MAO-B and have potential therapeutic value for the treatment of neurological disorders.

Supplementary Materials: The following are available online at https:/ /www.mdpi.com/article/ 10.3390/ph14111148/s1, Figure S1: Compound TM1 1H-NMR spectrum, Figure S2: Compound TM1 ESI MS spectrum, Figure S3: Compound TM8 1H-NMR spectrum, Figure S4: Compound TM8 ESI MS spectrum, Figure S5: Compound TM9 1H-NMR spectrum, Figure S6: Compound TM9 ESI MS spectrum, Figure S7: Compound TM10 1H-NMR spectrum, Figure S8: Compound TM10 ESI MS spectrum.

Author Contributions: Conceptualization: B.M. and H.K.; synthesis: B.M.; biological activity: J.M.O., A.K., M.A.A., T.M.R., G.E.M. and L.R.N.; molecular modeling: C.A. and M.E.S.S.; original draft writing: J.M.O. and B.M.; review and editing: H.K. and B.M.; supervision: H.K.; funding acquisition: B.M. and A.K. All authors have read and agreed to the published version of the manuscript.

Funding: This research was supported by a grant from Amrita Vishwa Vidyapeetham University (Seed Grant Number K-PHAR-20-628 to B. Mathew).

Institutional Review Board Statement: Not applicable.

Informed Consent Statement: Not applicable.

Data Availability Statement: Data are contained within the article and Supplementary Materials.

Acknowledgments: The authors acknowledge Taif University Researchers Supporting Project (Number: TURSP-2020/68), Taif University, Taif, Saudi Arabia.

Conflicts of Interest: The authors declare no conflict of interest.

\section{References}

1. $\quad$ De Lau, L.M.L.; Breteler, M.M.B. Epidemiology of Parkinson's disease. Lancet Neurol. 2006, 5, 525-535. [CrossRef]

2. Schapira, A.H.; Jenner, P. Etiology and pathogenesis of Parkinson's disease. Mov. Disord 2011, 26, 1049-1055. [CrossRef]

3. Rodriguez-Oroz, M.C.; Jahanshahi, M.; Krack, P.; Litvan, I.; Macias, R.; Bezard, E.; Obeso, J.A. Initial clinical manifestations of Parkinson's disease: Features and pathophysiological mechanisms. Lancet Neurol. 2009, 8, 1128-1139. [CrossRef]

4. Jankovic, J.; Aguilar, L.G. Current approaches to the treatment of Parkinson's disease. Neuropsychiatr. Dis. Treat 2008, 4, 743-757. [CrossRef] [PubMed]

5. Tipton, K.F. 90 years of monoamine oxidase: Some progress and some confusion. J. Neural. Transm. 2018, 125, 1519-1551. [CrossRef]

6. Carradori, S.; Secci, D.; Bolasco, A.; Chimenti, P.; D'Ascenzio, M. Patent-related survey on new monoamine oxidase inhibitors and their therapeutic potential. Expert Opin. Ther. Pat. 2012, 22, 909-939. [CrossRef] [PubMed]

7. Youdim, M.B.; Edmondson, D.; Tipton, K.F. The therapeutic potential of monoamine oxidase inhibitors. Nat. Rev. Neurosci. 2006, 7, 295-309. [CrossRef]

8. D'Amato, R.J.; Lipman, Z.P.; Snyder, S.H. Selectivity of the parkinsonian neurotoxin MPTP: Toxic metabolite MPP+ binds to neurtomelanin. Science 1986, 231, 987-989. [CrossRef] [PubMed]

9. Foley, P.; Youdim, M.B.H.; Riederer, P. MAO-B inhibitors: Multiple roles in the therapy of neurodegenerative disorders? Parkinsonism Relat. Disord. 2000, 6, 25-47. [CrossRef]

10. Ramsay, R.R. Inhibitor design for monoamine oxidases. Curr. Pharm. Des. 2013, 19, 2529-2539. [CrossRef]

11. Mathew, B.; Parambi, D.G.T.; Mathew, G.E.; Uddin, M.S.; Inasu, S.T.; Kim, H. Emerging therapeutic potentials of dual-acting MAO and AChE inhibitors in Alzheimer's and Parkinson's diseases. Arch. Pharm. Chem. Life Sci. 2019, 352, e1900177. [CrossRef] [PubMed]

12. Desideri, N.; Fioravanti, R.; Monaco, L.P.; Biava, M.; Yáñez, M.; Ortuso, F.; Alcaro, S. 1, 5-Diphenylpenta-2, 4-dien-1-ones as potent and selective monoamine oxidase-B inhibitors. Eur. J. Med. Chem. 2013, 59, 91-100. [CrossRef] [PubMed] 
13. Hagenow, J.; Hagenow, S.; Grau, K.; Khanfar, M.; Hefke, L.; Proschak, E.; Stark, H. Reversible small molecule inhibitors of MAO A and MAO B with anilide motifs. Drug Des. Dev. Ther. 2020, 28, 317-325. [CrossRef] [PubMed]

14. Kumar, S.; Nair, A.S.; Bhashkar, V.; Sudevan, S.T.; Koyiparambath, V.P.; Khames, A.; Abdelgawad, M.A.; Mathew, B. Navigating into the Chemical Space of Monoamine Oxidase Inhibitors by Artificial Intelligence and Cheminformatics Approach. ACS Omega. 2021, 6, 23399-23411. [CrossRef]

15. Palakkathondi, A.; Oh, J.M.; Dev, S.; Rangrajan, T.M.; Kaipakasseri, S.; Kavuly, F.S.; Gmabacorta, N.; Nicolotti, O.; Kim, H.; Mathew, B. (Hetero-)(arylidene) arylhydrazides as Multitarget-Directed Monoamine Oxidase Inhibitors. ACS Comb. Sci. 2020, 22, 592-599. [CrossRef] [PubMed]

16. Carradori, S.; Silvestri, R. New frontiers in selective human MAO-B inhibitors: Miniperspective. J. Med. Chem. 2015, 58, 6717-6732. [CrossRef] [PubMed]

17. Daina, A.; Michielin, O.; Zoete, V. SwissTargetPrediction: Updated data and new features for efficient prediction of protein targets of small molecules. Nucleic Acids Res. 2019, 47, W357-W3664. [CrossRef] [PubMed]

18. Guglielmi, P.; Mathew, B.; Secci, D.; Carradori, S. Chalcones: Unearthing their therapeutic possibility as monoamine oxidase B inhibitors. Eur. J. Med. Chem. 2020, 205, 112650. [CrossRef] [PubMed]

19. Zhuang, C.; Zhang, W.; Sheng, C.; Zhang, W.; Xing, C.; Miao, Z. Chalcone: A privileged structure in medicinal chemistry. Chem. Rev. 2017, 17, 7762-7810. [CrossRef]

20. Zhang, X.; Rakesh, K.P.; Bukhari, S.N.A.; Balakrishna, M.; Manukumar, H.M.; Ain, H.L. Multi-targetable chalcone analogs to treat deadly Alzheimer's disease: Current view and upcoming advice. Bioorg. Chem. 2018, 80, 86-93. [CrossRef]

21. Mathew, B.; Parambi, D.G.T.; Sivasankarapillai, V.S.; Uddin, M.D.S.; Suresh, J.; Mathew, G.E.; Joy, M.; Marathakam, A.; Gupta, S.V. Perspective design of chalcones for the management of CNS disorders: A mini-review. CNS Neurol. Disord. Drug Targets 2019, 18, 432-445. [CrossRef] [PubMed]

22. Mahapatra, D.K.; Asati, V.; Bharti, S.K. An updated patent review of therapeutic applications of chalcone derivatives (2014present). Expert Opin Ther. Pat. 2019, 29, 385-406. [CrossRef] [PubMed]

23. Chimenti, F.; Fioravanti, R.; Bolasco, A.; Chimenti, P.; Secci, D.; Rossi, F.; Yáñez, M.; Oraalo, F.; Ortuso, F.; Alcaro, S. Chalcones: A valid scaffold for monoamine oxidases inhibitors. J. Med. Chem. 2009, 52, 2818-2824. [CrossRef] [PubMed]

24. Mathew, B.; Uçar, G.; Mathew, G.E.; Mathew, S.; Purapurath, P.K.; Moolayil, F.; Mohan, S.; Gupta, S.V. Monoamine oxidase inhibitory activity: Methyl-versus chlorochalcone derivatives. Chem. Med. Chem. 2016, 11, 2649-2655. [CrossRef]

25. Shalaby, R.; Petzer, J.P.; Petzer, A.; Ashraf, U.M.; Atari, E.; Alasmari, F.; Kumarasamy, S.; Sari, Y.; Khalil, A. SAR and molecular mechanism studies of monoamine oxidase inhibition by selected chalcone analogs. J. Enzym. Inhib. Med. Chem. 2019, 34, 863-876. [CrossRef] [PubMed]

26. Parambi, D.G.T.; Oh, J.M.; Baek, S.C.; Lee, J.P.; Tondo, A.R.; Nicolotti, O.; Kim, H. Design, synthesis and biological evaluation of oxygenated chalcones as potent and selective MAO-B inhibitors. Bioorg. Chem. 2019, 93, 103335. [CrossRef] [PubMed]

27. Mathew, B.; Mathew, G.E.; Uçar, G.; Baysal, I.; Suresh, J.; Vilapurathu, J.K.; Prakasan, A.; Suresh, J.K.; Thomas, A. Development of fluorinated methoxylated chalcones as selective monoamine oxidase-B inhibitors: Synthesis, biochemistry and molecular docking studies. Bioorg. Chem. 2015, 62, 22-29. [CrossRef] [PubMed]

28. Morales-Camilo, N.; Salas, C.O.; Sanhueza, C.; Espinosa-Bustos, C.; Sepúlveda-Boza, S.; Reyes-Parada, M.; Gonzalez-Nio, F.; Caroli-Rezende, M.; Fierro, A. Synthesis, Biological Evaluation, and Molecular Simulation of Chalcones and Aurones as Selective MAO-B Inhibitors. Chem. Biol. Drug Des. 2015, 85, 685-695. [CrossRef]

29. Hammuda, A.; Shalaby, R.; Rovida, S.; Edmondson, D.E.; Binda, C.; Khalil, A. Design and synthesis of novel chalcones as potent selective monoamine oxidase-B inhibitors. Eur. J. Med. Chem. 2016, 114, 162-169. [CrossRef] [PubMed]

30. Mathew, B.; Mathew, G.E.; Uçar, G.; Joy, M.; Nafna, E.K.; Lohidakshan, K.K.; Suresh, J. Monoamine oxidase inhibitory activity of methoxy-substituted chalcones. Int. J. Biol. Macromol. 2017, 104, 1321-1329. [CrossRef]

31. Di, L.; Kerns, E.H.; Fan, K.; McConnell, O.J.; Carter, G.T. High throughput artificial membrane permeability assay for blood-brain barrier. Eur. J. Med. Chem. 2003, 38, 223-232. [CrossRef]

32. Thiruvalluvar, A.; Subramanyam, M.; Butcher, R.J.; Karabasanagouda, T.; Adhikari, A.V. (E)-1-[4-(Methylsulfanyl) phenyl]-3phenylprop-2-en-1-one. Acta Crystallogr. Sect. E Struct. Rep. 2008, 64, o1263. [CrossRef] [PubMed]

33. Kavully, F.S.; Oh, J.M.; Dev, S.; Kaipakasseri, S.; Palakkathondi, A.; Vengamthodi, A.; Azeez, R.F.A.; Tondo, A.R.; Nicolotti, O.; Kim, H. Design of enamides as new selective monoamine oxidase-B inhibitors. J. Pharm. Pharmacol. 2020, 72, 916-926. [CrossRef]

34. Baek, S.C.; Park, M.H.; Ryu, H.W.; Lee, J.P.; Kang, M.G.; Park, D.; Park, C.M.; Oh, S.R.; Kim, H. Rhamnocitrin isolated from Prunus padus var. seoulensis: A potent and selective reversible inhibitor of human monoamine oxidase A. Bioorg. Chem. 2018, 28, 317-325. [CrossRef]

35. Mathew, B.; Baek, S.C.; Parambi, D.G.T.; Lee, J.P.; Joy, M.; Rilda, P.R.A.; Randev, R.V.; Nithyamol, P.; Vijayan, V.; Inasu, S.T.; et al. Selected aryl thiosemicarbazones as a new class of multi-targeted monoamine oxidase inhibitors. Med. Chem. Comm. 2018, 9, 1871-1881. [CrossRef] [PubMed]

36. Park, C.; Cha, H.J.; Hong, S.H.; Kim, G.Y.; Kim, S.; Kim, H.S.; Kim, B.W.; Jeon, Y.J.; Choi, Y.H. Protective effect of phloroglucinol on oxidative stress-induced DNA damage and apoptosis through activation of the Nrf2/HO-1 signaling pathway in HaCaT human keratinocytes. Mar. Drugs 2019, 17, 225. [CrossRef] [PubMed]

37. Pérez, W.I.; Soto, Y.; Ortíz, C.; Matta, J.; Meléndez, E. Ferrocenes as potential chemotherapeutic drugs: Synthesis, cytotoxic activity, reactive oxygen species production and micronucleus assay. Bioorg. Med. Chem. 2015, 23, 471-479. [CrossRef] [PubMed] 
38. Knez, D.; Colettis, N.; Lacovino, L.G.; Sova, M.; Pišlar, A.; Konc, J.; Samo Lešnik, S.; Josefina Higgs, J.; Kamecki, F.; Mangialavori, I.; et al. Stereoselective activity of 1-propargyl-4-styrylpiperidine-like analogues that can discriminate between monoamine oxidase isoforms A and B. J. Med. Chem. 2020, 63, 1361-1387. [CrossRef] [PubMed]

39. Pettersen, E.F.; Goddard, T.D.; Huang, C.C.; Couch, H.G.S.; Greenblatt, D.M.; Meng, E.C.; Ferrin, T.E. UCSF Chimera-A visualization system for exploratory research and analysis. J. Comput. Chem. 2004, 25, 1605-1612. [CrossRef] [PubMed]

40. Trott, O.; Olson, A.J. AutoDock Vina: Improving the speed and accuracy of docking with a new scoring function, efficient optimization, and multithreading. J. Comput. Chem. 2010, 31, 455-461. [CrossRef] [PubMed]

41. Case, D.A.; Walker, R.C.; Huang, Y.; Lin, C.; Mermelstein, D.J.; Cheatham, T.E., III; Simmerling, C.; Li, P.; Roitberg, A.; Onufriev, A.; et al. AMBER 2018 Reference Manual. University of California, San Francisco. 2018. Available online: https: / / ambermd.org/doc12/Amber18.pdf (accessed on 10 October 2021).

42. Wang, J.; Wang, W.; Kollman, P.A.; Case, D.A. Automatic atom type and bond type perception in molecular mechanical calculations. J. Mol. Graph. Model 2006, 25, 247-260. [CrossRef] [PubMed] 